\title{
Organic Fertilizers and Biofertilizers to Improve Growth, Yield and Nutrient Quality of Soybean (Glycine max L.)
}

\author{
Samarakoon S.M.D.T. and Yapa P.N.* \\ Rajarata University of Sri Lanka, Mihintale, Sri Lanka \\ *pnyapa40@yahoo.co.uk
}

\begin{abstract}
Soybean (Glycine max L.) is one of the major legume crops cultivated in the dryzone of Sri Lanka. Most farmers use excess amounts of synthetic fertilizer to increase the yield of soybean and this causes serious health and environmental problems. Organic and biofertilizers can be used as an alternative, is a reliable solution for avoid the many of problems of synthetic fertilizer. The microbial consortium in the soil is critical to improve soil quality in agricultural fields. Organic residue recycling is becoming an increasingly important aspect of environmentally sound sustainable agriculture. Interactions of organic fertilizers with soil microorganisms are complex and improve the growth and yield of crops in tropical soil. The present study was conducted to find the effectiveness of organic and biofertilizers as an alternative to chemical fertilizer on growth yield and nutritional quality of soybean.
\end{abstract}

A pot experiment was carried out in plant house at Faculty of Applied Sciences Mihintale, dryzone of Sri Lanka. Treatments were field soil only $\left(\mathrm{T}_{0}\right)$, field soil and $5 \%$ biochar $\left(\mathrm{T}_{1}\right)$, field soil and 5\% cow dung $\left(\mathrm{T}_{2}\right)$, field soil, $2.5 \%$ biochar and $2.5 \%$ cow dung $\left(\mathrm{T}_{3}\right)$, field soil, $5 \%$ biochar and Bradyrhizobium $\left(\mathrm{T}_{4}\right)$, field soil, $5 \%$ biochar and mycorrhizae $\left(\mathrm{T}_{5}\right)$, field soil, 5\% cow dung and Bradyrhizobium ( $\left.\mathrm{T}_{6}\right)$ field soil, $5 \%$ cow dung and mycorrhizae $\left(\mathrm{T}_{7}\right)$, field soil and synthetic fertilizer $\left(\mathrm{T}_{8}\right)$, field soil, $2.5 \%$ cow dung $2.5 \%$ biochar and synthetic fertilizer $\left(\mathrm{T}_{9}\right)$, field soil, $5 \%$ cow dung, mycorrhizae and Bradyrhizobium $\left(\mathrm{T}_{10}\right)$, field soil, $5 \%$ biochar, mycorrhizae and Bradyrhizobium $\left(\mathrm{T}_{11}\right)$. The treatments were tested in a Completely Randomized Block Design (CRBD) with six replicates.

Considering the growth, significantly high $(\mathrm{p}<0.05)$ initial relative growth rate, number of leaflets, root dry weight, shoot dry weight, nodule dry weight was observed in $\mathrm{T}_{9}$, the addition of $2.5 \%$ cow dung, $2.5 \%$ biochar and synthetic fertilizer. Soybean yield such as number of pods and dry weight of 100 seeds were significantly high $(\mathrm{p}<0.05)$ in $\mathrm{T}_{10}$, the addition of field soil, 5\% cow dung, mycorrhizae and Bradyrhizobium. Higher seed protein percentage was observed in $\mathrm{T}_{10}$, fat percentage in $\mathrm{T}_{4}$ and crude fiber percentage in $\mathrm{T} 8$ treatments. It can be concluded that yield and nutrient quality of soybean can be enhanced by the application of organic and biofertilizers together. This provides optimism for applying organic and biofertilizers on sustainable agricultural practices in dryzone of Sri Lanka.

Keywords: Biofertilizers, Organic fertilizers, Glycine max, Growth, Yield, Nutrient quality

Proceedings of the International Forestry and Environment Symposium 2016, Department of Forestry and Environmental Science, University of Sri Jayewardenepura, Sri Lanka. 